\title{
A comparative analysis of air pollutant concentrations and inflow trajectories: a case study of selected cities in South-Eastern Poland
}

\author{
Robert Oleniacz ${ }^{1, *}$, Tomasz Gorzelnik ${ }^{1}$, and Adriana Szulecka $^{1}$ \\ ${ }^{1}$ AGH University of Science and Technology, Faculty of Mining Surveying and Environmental \\ Engineering, Department of Environmental Management and Protection, Krakow, Poland
}

\begin{abstract}
The paper presents a comparison of air pollutant concentrations in three cities in South-Eastern Poland (Krakow, Tarnow and Rzeszow) using statistical analyses and backward trajectory modelling (the HYSPLIT model). The analyses were based on particulate matter $\left(\mathrm{PM}_{10}\right)$, nitrogen dioxide $\left(\mathrm{NO}_{2}\right)$ and sulphur dioxide $\left(\mathrm{SO}_{2}\right)$ levels as well as meteorological data from year 2017. The performed analyses revealed, among others, that the $\mathrm{PM}_{10}$ and $\mathrm{SO}_{2}$ concentrations in the air depend on the season of the year, while the $\mathrm{NO}_{2}$ concentrations are seasonally independent, which is mainly associated with emissions from road transport. Air quality in the analysed cities depends on local meteorological conditions and the structure of emission sources, including the inflowing background. The most unfavourable situation regarding high concentrations of $\mathrm{PM}_{10}$ and $\mathrm{NO}_{2}$ occurs in Krakow. For all analysed urban background stations very similar low $\mathrm{SO}_{2}$ air concentrations are observed which proves the decreasing significance of emissions from coal combustion sources.
\end{abstract}

\section{Introduction}

High pollutant concentrations in the air constitute a substantial issue in many Polish cities, especially those located in the southern part of the country. Air quality in this region has improved significantly over the last 25 years in the case of, i.a. observed levels of sulphur dioxide $\left(\mathrm{SO}_{2}\right)$. However, in the case of the $\mathrm{PM}_{10}$ fraction of particulate matter and nitrogen dioxide $\left(\mathrm{NO}_{2}\right)$, during this period high concentrations were observed with some fluctuations [1-3]. Particularly noteworthy is $\mathrm{PM}_{10}$, whose air concentrations in many cities of Southern Poland usually exceed the permissible annual and daily values (especially in winter), and the levels of benzo(a)pyrene inside this fraction are among the highest in Europe [3-5].

The largest city in this region, struggling with severe air pollution, is Krakow, the capital of the Malopolska voivodeship. In this city a dense air quality monitoring network was developed and operating as a part of the State Environmental Monitoring [3]. Poor air quality in Krakow, associated with excessive dust concentrations and poor ventilation conditions [6], is observed primarily in the heating season, hence until now it was mainly identified with domestic fuel combustion for heating needs. Meanwhile, the role of these

\footnotetext{
*Corresponding author: oleniacz@agh.edu.pl
} 
emission sources in the shaping process of air quality in Krakow is becoming more and more marginal due to a long-term program aimed at replacing low-power boilers and furnaces fuelled by coal or wood with more environmentally friendly solutions: gas, electric or grid heating. The approaching absolute ban on the combustion of solid fuels in this type of hearths in the city, set as at 01.09.2019, constitutes yet another incentive [7]. Thus, the role of other local emission sources (road transport and industrial plants) and the inflowing background, whose significance seems to be underestimated, is growing.

The unfavourable location of Krakow in a low area (the valley of the Vistula river surrounded by hills) and its densely built environment result in a significant reduction of the average wind speed and an increase of wind silence periods in relation to areas outside the city perimeter. The paper is an attempt to provide an answer to what extent such conditions affect the $\mathrm{PM}_{10}, \mathrm{NO}_{2}$ and $\mathrm{SO}_{2}$ air concentrations, and how important can solely the size of the city be, local emission sources and background. It was based on a comparative analysis carried out also taking into account the situations occurring in two cities located near Krakow on the same latitude (Tarnow and Rzeszow), and are characterized by better air quality. The analysis was extended with the results of backward trajectory modelling using the HYSPLIT model and a clustering tool to determine the dominant directions of air masses inflow for the cities and to illustrate the long-term trends. The modelling of back trajectories in conjunction with air pollution state analysis has already been applied in some Polish cities [8-12]. Utility of this type of analysis was also demonstrated for, e.g. the urban background station in Bari (Italy) [13], natural continental background station in Puy de Dôme (France), Schauinsland (Germany) and Sonnblick (Austria) [14], and the rural background station in Košetice (Czech Republic) [15].

\section{Materials and methods}

A comparative analysis of the air pollutant concentrations and the trajectories of their possible inflow was carried out for three selected cities (Krakow, Tarnow and Rzeszow) located in South-Eastern Poland. Their central points are located on a similar latitude (about $50^{\circ} 01^{\prime}-50^{\circ} 04^{\prime} \mathrm{N}$ ) and the absolute altitude (about 210-220 $\mathrm{m}$ a.s.1.), at a distance of about $70-75 \mathrm{~km}$ from each other (in a straight line). The largest of the analysed cities (Krakow) has 765000 residents and an area of $327 \mathrm{~km}^{2}$, Tarnow has a population of 110000 and an area of $72 \mathrm{~km}^{2}$ and Rzeszow is inhabited by 187000 people with an area of $117 \mathrm{~km}^{2}$ (as of 31.12.2016) [16].

The analyses were carried out for 2017 based on data from automatic measurements of $\mathrm{PM}_{10}, \mathrm{NO}_{2}$ and $\mathrm{SO}_{2}$ concentrations conducted by the Inspection for Environmental Protection at air quality monitoring stations [3]. In the case of Krakow, two traffic stations and four urban background stations were considered, and for the purpose of further analyses their results were averaged for a given type of station. In the case of Tarnow, the results of measurements from one traffic and one urban background station (the only stations operating in the city) were used in the analyses, and in the case of Rzeszow - only the results from a single urban background station (due to the lack of a traffic station in this city). In addition, meteorological data were included in the analysis and derived from the weather stations of the Institute of Meteorology and Water Management (IMGW) located in the vicinity of Krakow and Rzeszow (airport stations) and in the city centre of Tarnow, as well as from the weather station belonging to the AGH University of Science and Technology in Krakow situated in the city centre at an altitude of approx. $16 \mathrm{~m}$ a.g.l.

The work focused on the comparison of concentrations of the analysed pollutants in the air of the considered cities, averaged for particular types of the air quality stations. Statistical analyses were carried out, and subsequently their results were visualised with boxplots using the $\mathrm{R}$ programming language [17, 18]. The variability of concentrations 
during the day, week and calendar year was also presented. Wind speed and direction were used to compare meteorological conditions occurring in the assessed period in the analysed cities or on their outskirts. The analyses were extended by examination of the main trajectories of the possible pollutants inflow over the considered area. This assessment was carried out using the HYSPLIT model [19] and the openair package [18], whose functionalities allowed grouping the calculated back trajectories in the clustering process.

\section{Results and discussion}

\subsection{The variability of the pollutant concentrations in the air}

Basic data on the results of measurements of air pollutant concentrations in 2017 for the considered air quality monitoring stations are presented in Table 1. In Fig. 1 the boxplots with the 24-hour $\left(\mathrm{PM}_{10}, \mathrm{SO}_{2}\right)$ and 1-hour $\left(\mathrm{NO}_{2}\right)$ concentration distributions obtained for the same year and divided into winter and summer halves are shown, but for the $\mathrm{PM}_{10}$ concentrations and in the case of Krakow, all data from four of the urban background air quality stations were considered. The outliers were excluded from the data and not shown on the boxplots. The top and the bottom whiskers mean, respectively, the maximum and minimum value, the top and the bottom sides of the rectangle represent third and first quartile and the central bar means the median. Figures 2 and 3 present the temporal variability of the concentrations for the considered substances and analysed cities, with the $\mathrm{PM}_{10}$ values averaged for given station types in the case of Krakow.

Table 1. General characteristics of the air quality state for the analysed cities in 2017 in terms of $\mathrm{PM}_{10}, \mathrm{SO}_{2}$ and $\mathrm{NO}_{2}$ concentrations.

\begin{tabular}{|c|c|c|c|c|c|c|c|c|c|}
\hline \multirow[b]{2}{*}{$\begin{array}{c}\text { Air quality } \\
\text { monitoring } \\
\text { station / } \\
\text { parameter }\end{array}$} & \multicolumn{3}{|c|}{$\mathbf{P M}_{10}$} & \multicolumn{3}{|c|}{$\mathrm{NO}_{2}$} & \multicolumn{3}{|c|}{$\mathrm{SO}_{2}$} \\
\hline & 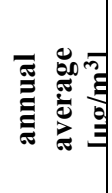 & 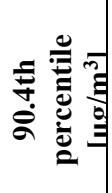 & 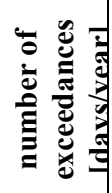 & 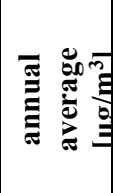 & 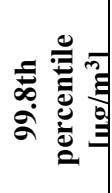 & 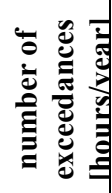 & 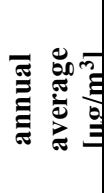 & 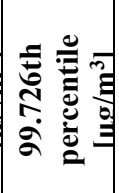 & 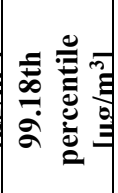 \\
\hline $\begin{array}{c}\text { Krakow - traffic } \\
\text { station } \# 1\end{array}$ & 55 & 104.3 & 131 & 61 & 153.3 & 0 & - & - & - \\
\hline $\begin{array}{c}\text { Krakow - traffic } \\
\text { station } \# 2\end{array}$ & 49 & 88.0 & 106 & 42 & 144.9 & 1 & - & - & - \\
\hline $\begin{array}{c}\text { Tarnow - traffic } \\
\text { station }\end{array}$ & 38 & 76.3 & 74 & 32 & 115.8 & 0 & - & - & - \\
\hline $\begin{array}{c}\text { Krakow - urban } \\
\text { background* }\end{array}$ & 41.5 & 79.0 & 78 & 33 & 138.8 & 0 & 7.1 & 71.2 & 50.0 \\
\hline $\begin{array}{c}\text { Tarnow - urban } \\
\text { background }\end{array}$ & 31 & 66.4 & 53 & 23 & 93.0 & 0 & 7.3 & 58.3 & 34.5 \\
\hline $\begin{array}{c}\text { Rzeszow - urban } \\
\text { background }\end{array}$ & 30 & 55.9 & 48 & 18 & 95.2 & 0 & 6.2 & 57.2 & 31.6 \\
\hline Limit value & 40 & 50 & 35 & 40 & 200 & 18 & 20 & 350 & 125 \\
\hline
\end{tabular}

* in the case of $\mathrm{PM}_{10}$, the average value from four of the urban background stations

The exceedances of the 24-hour permissible level of $\mathrm{PM}_{10}$ were observed at all of the considered monitoring stations in 2017. The highest number of days with exceedances occurred in Krakow, where the concentrations over the limit value persisted for more than 100 days during the year at one of the traffic stations. Also the annual limit value for the 
$\mathrm{PM}_{10}$ concentrations was exceeded in Krakow. In the case of $\mathrm{NO}_{2}$, its permissible annual level was exceeded at both traffic stations in Krakow. However, for the traffic station in Tarnow and the urban background stations in Krakow, the annual mean $\mathrm{NO}_{2}$ concentration in the air was almost the same and reached $80-83 \%$ of the limit value, and at the urban background station in Rzeszow it was only $45 \%$ of the permissible value. Limit values for the $\mathrm{SO}_{2}$ air levels were met in all the analysed cities. The highest calculated percentile of 99.726 and 99.18 from the 1-hour $\mathrm{SO}_{2}$ concentrations, which correspond to the permitted exceedance frequency of the 1-hour and 24-hour limits, respectively, occurred in Krakow, whereas in Tarnow and Rzeszow they remained at a clearly lower and similar level.
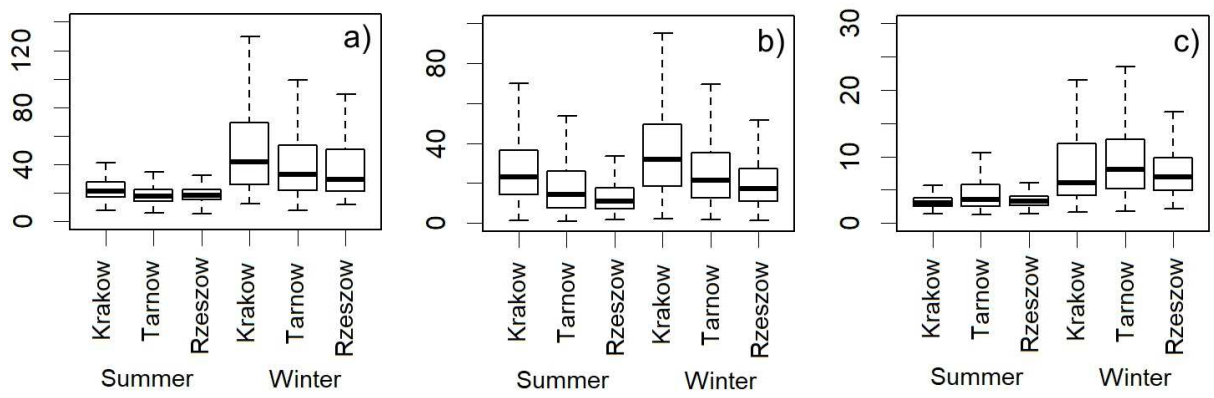

Fig. 1. The boxplots showing the distributions of the: a) 24-hour $\mathrm{PM}_{10}$, b) 1-hour $\mathrm{NO}_{2}$ and c) 24-hour $\mathrm{SO}_{2}$ air concentrations for the analysed cities (urban background stations) in $2017\left[\mu \mathrm{g} / \mathrm{m}^{3}\right]$.

The analysis of the boxplots (Fig. 1) allowed observing the differences in the variability of the $\mathrm{PM}_{10}$ and $\mathrm{SO}_{2}$ concentrations depending on a half-year. In the cold period, the median value of the $\mathrm{PM}_{10}$ concentrations is even twice as high as in the warm period of the year. The median value of the $\mathrm{SO}_{2}$ concentration for all the analysed cities remain at similar level throughout the year, but the spread of values vary significantly in the considered halfyears. In the case of the $\mathrm{NO}_{2}$ concentrations, the differences in statistical parameter values shown in the graphs in the winter and summer half-year are less noticeable. This results from the fact that the formation of $\mathrm{NO}_{2}$ in the air of the considered cities depends to a great extent on the road transport emissions, which remain on an approximately constant level throughout the year. This is confirmed by the results of the measurement of the $\mathrm{NO}_{2}$ concentrations observed at traffic stations (Table 1), which are about 30-80\% higher than the $\mathrm{NO}_{2}$ occurring at urban background stations in a chosen city.

The averaging of the $\mathrm{PM}_{10}$ and $\mathrm{NO}_{2}$ air concentrations for the particular cities allowed concluding that their values decrease in the following order: Krakow, Tarnow, Rzeszow, but this tendency is more visible during the cold half-year. The quantile range (IQR) varies in the same order. Only for the $\mathrm{SO}_{2}$ values, those measured in Tarnow are the highest among the three analysed cities. The $\mathrm{NO}_{2}$ concentrations indicate clear diurnal fluctuations (road transport impact). Minimum values occur around 5:00 in the morning (CET), while the maximum values appear in the evening hours (Fig. 2). The diurnal variability of the $\mathrm{PM}_{10}$ concentrations is slightly different, for which similar fluctuation is observed, but the daily maximum value appears before midday, and the minimum value occurs in the afternoon. During the annual cycle, a certain independence of the $\mathrm{NO}_{2}$ concentrations from the season and a significant increase in the values near transport routes are noticeable, which confirm the conclusions drawn from the previous analysis. The $\mathrm{PM}_{10}$ concentrations observed in the vicinity of the transport routes in Krakow and Tarnow are about $20-30 \%$ higher than those measured at urban background stations in the same cities. The average $\mathrm{PM}_{10}$ concentrations at the urban background stations in Krakow are similar to the average $\mathrm{PM}_{10}$ concentrations at the traffic station in Tarnow, and even meaningfully higher during the early morning hours to early afternoon hours. This is the evidence of how significant 
the road transport emissions are in a large city with a dense traffic flow like Krakow in terms of the $\mathrm{PM}_{10}$ pollution. After comparing the temporal variability of the $\mathrm{PM}_{10}$ and $\mathrm{SO}_{2}$ air levels in the vicinity of urban background stations in the considered cities, it can be noticed that these locations may be exposed to the same impact of domestic coal-fired furnaces, and some differences in the heating season (observed in the case of $\mathrm{PM}_{10}$ ) may result from the specificity of the local meteorological conditions and diversified impact of the other emission sources (wood-fired furnaces, road transport and industrial plants).
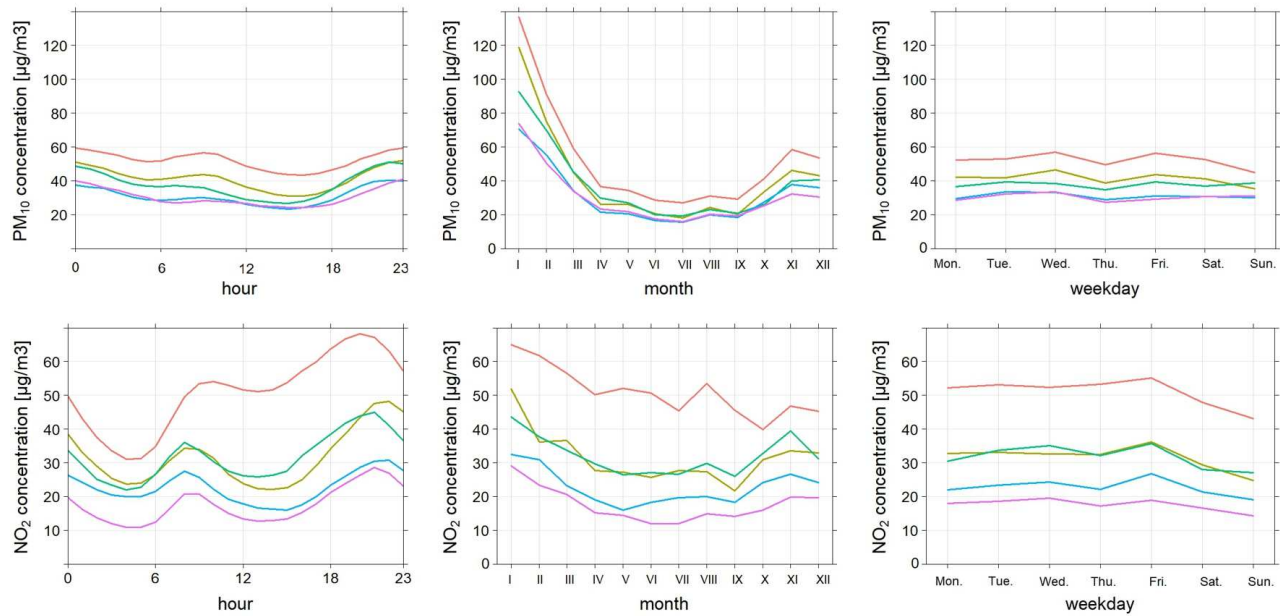

Krakow - traffic

Krakow - urban background

Tarnow - urban background

Rzeszow - urban background

Fig. 2. The variability of the 1-hour $\mathrm{PM}_{10}$ and $\mathrm{NO}_{2}$ concentrations in the air for the analysed cities in 2017 averaged for hours of the day, months and days of the week.
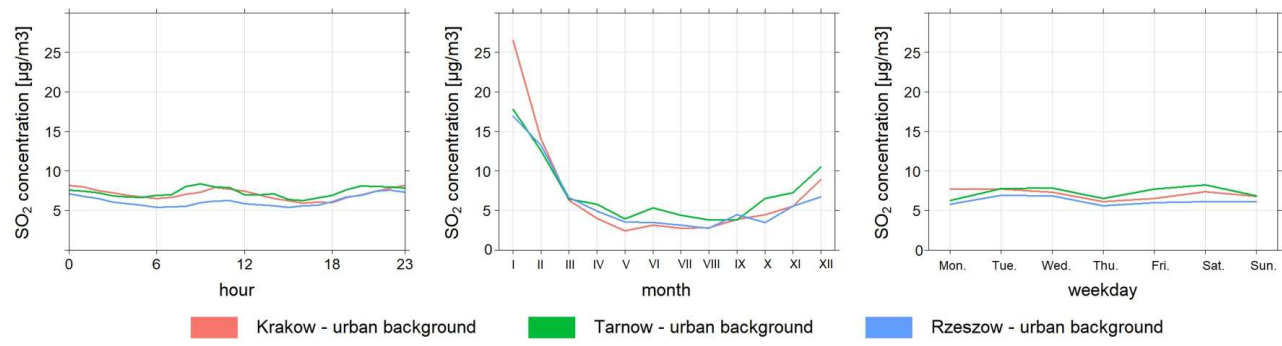

Fig. 3. The variability of the 1-hour $\mathrm{SO}_{2}$ concentrations in the air for the analysed cities in 2017 averaged for hours of the day, months and days of the week.

\subsection{The analysis of wind conditions and back trajectories}

In Fig. 4 and 5, respectively, the wind speed distributions (as boxplots) in 2017 and yearly wind roses are presented for considered meteorological stations. The average annual wind speed measured at the airport meteorological station located outside the city of Krakow in Balice (Krakow IMGW) is about $1.4 \mathrm{~m} / \mathrm{s}$ higher than in the city centre (Krakow AGH). The average annual wind speed in the area of Krakow at lower altitudes (compared to the meteorological standard) are even smaller and predominantly slightly above $1 \mathrm{~m} / \mathrm{s}$ [6]. At the meteorological stations Krakow AGH and Tarnow IMGW a much smaller spread of measured wind speed values is observed than at other IMGW stations (Fig. 4). This is due to the location of the Krakow and Rzeszow IMGW stations outside the city in the open 
space (airport stations), where high wind speeds are more frequent. Despite the fact, that in the centre of Tarnow the wind speeds are equally as low as in the city of Krakow, in Tarnow the exceedances of the annual $\mathrm{PM}_{10}$ and $\mathrm{NO}_{2}$ limit values are not observed, unlike in Krakow. This may stem from, among others, the size of the city and the smaller accumulation of local sources in Tarnow in relation to Krakow. Considering the fact, that in Krakow an intensive program aimed at the liquidation of domestic furnaces fired with solid fuels has been in progress for several years, the main sources of the emission responsible for high concentrations of $\mathrm{PM}_{10}$ and $\mathrm{NO}_{2}$ in the air seem to be road transport, since the total streets length and the traffic volume in Krakow are much bigger than in Tarnow.

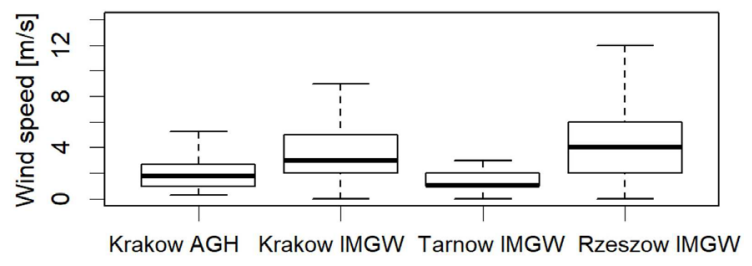

Fig. 4. The boxplot showing the wind speed distribution for the analysed weather stations in 2017.

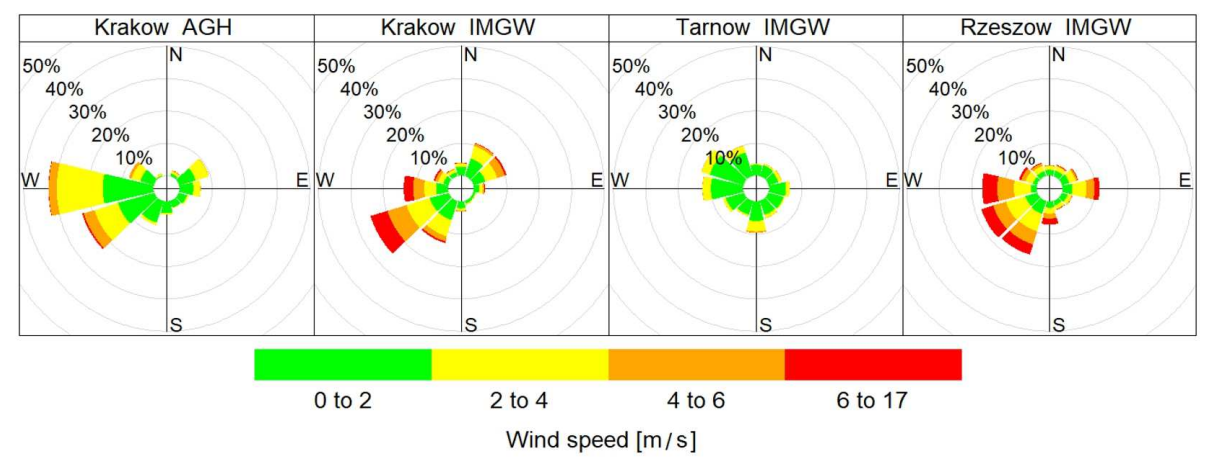

Fig. 5. The wind roses of the wind conditions in the area of the weather stations in 2017.

Although Rzeszow is a larger city than Tarnow, the air in this city appears to be of an even better quality. The location conditions in relation to the local emission sources and the inflowing background may be meaningful here. As deduced from the wind roses (Fig. 5), the western and south-western wind directions are dominant in Krakow. Similar conditions can be observed in Rzeszow. However, in Tarnow mostly winds blowing from the eastern, north-eastern and southern directions were found, which may constitute another reason for the diversified air quality in this city in relation to, for example, Krakow.

In Fig. 6 the 48-hour backward trajectories of the inflowing air masses at the altitude of $10 \mathrm{~m}$ a.g.l. for the three discussed locations are presented. The trajectories were calculated for every hour in 2017 and subsequently grouped into five clusters depending on the direction of inflow of the air masses. The shape and length of the trajectory clusters are very similar for all three cities, most probably due to the close position of the endpoints and the coarse grid of the meteorological data used (with the resolution of $2.5^{\circ} \times 2.5^{\circ}$ ). Nevertheless, in this region the vast majority of the incoming air masses during the year comes from the western and southern directions (C3, C4 and C5 clusters), which is characteristic for this region of Europe. Based on the length of the trajectories, the western direction is associated with air masses of a higher velocity and originating from further distances, including neighbouring voivodeships of Poland, and to some extent from other countries (i.e. from Czech Republic or Germany). The southern direction is associated with the winds of a much lower speed, which can transport air masses polluted mainly by the 
local emission sources in addition to those originating from Slovakia and Hungary. The main reason behind low wind speeds from this direction is the presence of the Carpathian mountain chain located along the Polish-Slovakian border, which creates a natural obstacle for the masses of air flowing from the southern parts of Europe.

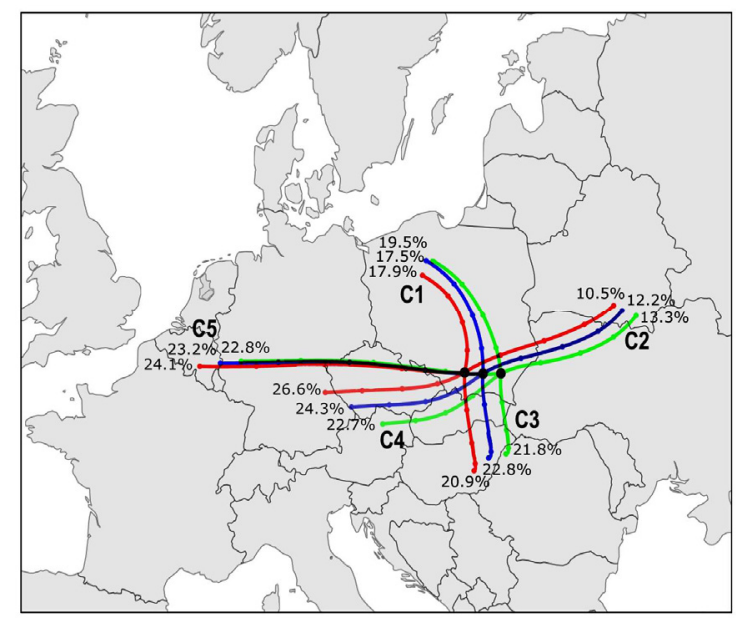

Fig. 6. 48-hour back trajectories of the air masses determined using the HYSPLIT model for 2017 and for the analysed cities (red colour - Krakow, blue - Tarnow, green - Rzeszow) grouped into 5 clusters.

The presented backward trajectory analysis shows that only during the winds from the west (cluster C5), pollutants originating from the same regions can reach all of the analysed cities. The dissimilarities in the pollutant concentrations observed in the considered cities at different timestamps may therefore partly result from divergent loadings reaching the endpoints with the inflowing air masses at a given wind direction due to the occurrence of local emission sources creating the inflowing background.

\section{Conclusions}

The conducted analyses allowed noting, that the $\mathrm{PM}_{10}$ and $\mathrm{SO}_{2}$ concentrations in the air of the considered cities located in South-Eastern Poland (Krakow, Tarnow and Rzeszow) largely depend on the time of year, which is often explained by the presence of the socalled heating and non-heating periods. The variation of the $\mathrm{NO}_{2}$ concentrations in the air is constant throughout the year in each of the analysed cities, yet it is characterised by a strong diurnal variation (revealing the clear influence of local road transport). The exceedances of the air quality standards are the issue of, almost exclusively, the measurement stations located in Krakow. This situation is particularly unfavourable in the heating season and it may be intensified by the specific meteorological conditions (including low wind speed).

In general, the pollutant concentrations in the cities decrease in the following order: Krakow, Tarnow, Rzeszow. In Krakow, which is definitely the largest of the analysed cities, the concentrations of $\mathrm{PM}_{10}$ and $\mathrm{NO}_{2}$ at traffic stations are significantly higher in relation to the measurements from the urban background stations, and the latter are exposed to high levels of these substances from the local road traffic, undoubtedly higher than in the case of Tarnow or Rzeszow. In addition to the generally poor ventilation conditions occurring in such a densely built-up city as Krakow, this factor seems to be the main reason for worse air quality in Krakow. It can be indirectly confirmed by the low concentration of $\mathrm{SO}_{2}$ in the air as well, which is very similar in all the analysed cities, thus there is no difference in the impact of emissions from the local coal-fired furnaces at all the locations. 
On the other hand, this does not negate a certain dependence of the $\mathrm{PM}_{10}$ concentrations in the cities on its inflowing background. The analysis of the air masses trajectory clusters for the three discussed cities revealed a great similarity of the inflows, which, to some extent, may be burdened with the inaccuracy of the meteorological data used. The predominant inflow directions (western, west-southern and southern) grouping almost $2 / 3$ of all trajectories are typical in western and northern Europe. A detailed analysis of the trajectories from the west and the corresponding air pollution in the considered locations could potentially help identify and track the inflow of pollutants from neighbouring cities, as the determined $\mathrm{C} 5$ cluster for the urban background station in Rzeszow, grouping almost $23 \%$ of the 48 -hour trajectories from the west also crosses the remaining two cities.

The paper has been prepared within the scope of AGH UST statutory research no. 11.11.150.008.

\section{References}

1. A. Bokwa, Pol. J. Environ. Stud., 17, 673 (2008)

2. D. Cichoń, S. Hławiczka, Ochrona Powietrza i Problemy Odpadów, 44, 133 (2010)

3. Chief Inspectorate of Environmental Protection in Poland, Air Quality Portal (http://powietrze.gios.gov.pl, access: April 9, 2018)

4. W. Rogula-Kozłowska, B. Kozielska, K. Klejnowski, Arch. Environ. Prot., 39, 53 (2013)

5. EEA, Air quality in Europe - 2016 report (EEA Report No 28, 2016)

6. R. Oleniacz, M. Bogacki, A. Szulecka, M. Rzeszutek, M. Mazur, JCEEA, 33, 315 (2016)

7. The LIFE-IP project Malopolska, Małopolska in a Healthy Atmosphere (https://powietrze.malopolska.pl/en/anti-smog-resolution, access: April 9, 2018)

8. A. Worobiec, A. Zwoździak, I. Sówka, J. Zwoździak, E.A. Stefaniak, A. Buczyńska, A. Krata, K. van Meel, R. van Grieken, M. Jędrysek, Environ. Prot. Eng., 34, 81 (2008)

9. M. Reizer, K. Juda-Rezler, Air Qual. Atmos. Health, 9, 517 (2016)

10. B. Czernecki, M. Półrolniczak, L. Kolendowicz, M. Marosz, S. Kendzierski, N. Pilguj, J. Atmos. Chem., 74, 115 (2017)

11. P. Siudek, Atmos. Poll. Res. (2018) https://doi.org/10.1016/j.apr.2018.01.001

12. A. Szulecka, R. Oleniacz, M. Rzeszutek, Environ. Prot. Nat. Resources, 28, 22 (2017)

13. A. Di Gilio, G. De Gennaro, P. Dambruoso, G. Ventrella, Sci. Total Environ. 530-531, 28 (2015)

14. P. Salvador, B. Artíñano, C. Pio, J. Afonso, M. Legrand, H. Puxbaum, S. Hammer, Atmos. Environ., 44, 2316 (2010)

15. S. Mbengue, M. Fusek, J. Schwarz, P. Vodička, A.H. Šmejkalová, I. Holoubek, Atmos. Environ., 182, 335 (2018)

16. Statistical Information Centre in Poland, Statistics Poland (http://stat.gov.pl/en/, access: April 9, 2018)

17. The R Foundation, The R Project for Statistical Computing (https://www.r-project.org, access: April 9, 2018)

18. D.C. Carslaw, K. Ropkins, Environ. Model. Softw. 27-28, 52 (2012)

19. A.F. Stein, R.R. Draxler, G.D. Rolph, B.J.B. Stunder, M.D. Cohen, F. Ngan, Bull. Amer. Meteor. Soc., 96, 2059 (2015) 